\title{
The Impact of Using of the Dry Laboratory Based on the Theory of Green Education in the Teaching of Chemistry in the Acquisition of Science and Achievement of Students in the Tenth Grade in Amman City
}

\author{
Dr. Fawaz Shehadeh \\ Associate Professor, University of the Middle East \\ Dr. Abdullah Shehab \\ Assistant Professor, University of Taiba
}

\begin{abstract}
The study aimed at investigating the effectiveness of teaching of Chemistry, by using dry lab based on green education theory, on acquisition of science and the achievement of students in the tenth grade in Amman. The study consisted of 40 students, distributed into two groups; experimental group (20) students taught by using dry lab and the other (20) students as control group taught by traditional method. The results of the study revealed statistical significant differences between the averages of acquisition of science and achievement of students for both experimental and control groups due to the teaching method. In the light of the results, the researchers recommended to apply studies which investigate the effect of using dry lab related to some variables such as attitudes of students toward chemistry.
\end{abstract}

Keywords: Dry lab, Acquisition of science. Achievement

DOI: $10.7176 / \mathrm{JEP} / 10-27-09$

Publication date:September $30^{\text {th }} 2019$

\section{Introduction}

The society of the present age is faced with a series of challenges, changes and rapid developments in various fields of life, technological revolution, economy, knowledge economy, green economy and green education, and the employment of information and communication technologies to cope with these challenges and developments in order to prepare citizens for life in the 21 st century. The individual has to think and refine his mind and behavior to be able to serve his community and nation.

Modern education is based on adaptation to information and communication technologies. So, educational systems face the same challenge of adapting the curriculum periodically to rapid and large technological leapfrogs, as well as preparing students and teachers for the use of technology in the educational learning process to achieve the desired benefit.

Therefore, educators in science curricula and teaching strategies emphasize that the learning process is no longer merely a transfer of knowledge to the learner. Rather, it is important to focus on teaching based on the use of modern educational methods and contemporary technologies, in line with scientific progress and human development. Through the continuous participation between the learner and the computer, the employment of modern software in education has a clear impact through the books on the strategies of teaching, especially related to girls and active learning and based on the theory of education (Zaitoun , 2015).

The role of computers as an educational tool is seen in emphasizing modern educational trends on selflearning, increasing the student's responsibility for learning, and increasing the need to separate education to suit its abilities and needs and to take account of individual differences among students. Psychologically and logically, it provides an atmosphere of direct interaction in the learning process (Salama Abdel Hafez, 2016).

Lab Dry is one of the most important computer applications, allowing both students and teachers to experiment and execute without risk or cost, with the possibility of repeating and replaying the experiment more than once. Chemistry is one of the most scientific branches with highly abstract concepts, making the dry laboratory a way of compensating for the theoretical aspect of the nature of chemistry and thus acquiring students' chemical concepts properly (Samara Al-Adaily, 2018).

Virtual labs are one of the fruits of integrating technology into science education, innovation in technology in education, and an extension of electronic simulation systems to be used to address some of the problems facing science teaching. One of such is hazardous experiments, where the dry laboratory closely simulates the real laboratory in its functions and events through which results are obtained similar to the results of the actual laboratory. Interactive virtual learning and learning environments simulate real labs by applying scientific experiments by default to mimic the real application of the experiment, in order to equip students with the processes of science, laboratory, and group work skills so that they can carry out costly scientific experiments and experiments that needs a long time to accomplish, watching interactions and results without risk, effort, and 
cost (Martines, 2003). Ali (2003) notes that laboratory experience plays an essential role in the teaching and learning of chemistry and it is difficult to accept an effective method of teaching chemistry without the use of experiments and laboratory exercises. The Dry Lab method is an important and effective method used in teaching science in general and chemistry in particular. However, in some cases, it may not be possible to conduct the experiment in a realistic manner by the students for reasons that may be related to the seriousness of the experiment, the difficulty of conducting it, or that it requires expensive tools and devices, the lack of validity of the equipment. It may also be due to the lack of time to prepare for the experiment's interactive process. This is difficult to achieve through the real laboratory due to the limited possibilities, space, and time available to the practical side.

Dry laboratories are characterized by the lack of real laboratory capabilities, the possibility of conducting serious experiments that are difficult to implement in real laboratories, the possibility of visual presentation of data and phenomena that cannot be presented through real experiments, as well as the ease of experimenting with different factors and their impact on the outputs of the experiment. Other limitations arrive in providing appropriate feedback, flexibility in testing and cost savings by providing consumables such as chemicals, laboratory methods and components of experiments, protecting the learner from the risks of practical training at the beginning of stages, and protecting the facilities from the risk of beginners' wrong practices. The fact that an element of attraction and excitement characterizes dry experiments encourages the integration of students in the learning process (The National Center for e-Learning, 2010).

Green education, the so-called school or the green university, is the modern education that seeks sustainable development, keeping abreast of the technological development, and benefiting from it in all elements of the educational process with high efficiency and outstanding products according to environment-friendly standards. It develops environmental programs from buildings, energy, landscaping and services, as well as developing everything that focuses on the educational process with the technology, applications, strategies, and practices associated with the concept of green education. Many countries have started to adopt it in their institutions and educational system. Dry laboratories are tools that support green education philosophy and provide a secure environment for communication and collaboration, and the exchange of educational content and its applications (Ahmed, Hassan \& Gamal El-Din, 2014).

The previous studies on the effect of the method of dry laboratory, the study of Samara, Adaily and Saudi (2018) aimed at detecting the effectiveness of teaching dry laboratory in the acquisition of chemical concepts in the students enrolled in the course of general chemistry practical at the University of Mutah. Out of 105 students of the study, forty-four (44) were chosen. A pilot group was selected consisting of twenty-two (22) students who studied the chemical experiments using the dry laboratory, and the other division was a group of twenty (20) students who studied in the usual manner.

The result of the study showed that there were no significant differences between the average performance of students in the experimental group and the control group on the post-achievement test due to the teaching method.

Dar Ibrahim (2014) conducted a study aimed at investigating the effect of the use of the virtual laboratory of science experiments in the development of science processes and acquisition of concepts among fifth grade students in Palestine. The study sample consisted of (40) students; it was divided into two groups: the first was an experimental group. Twenty (20) students who were taught according to the method of using the virtual lab, and the second was an officer of twenty (20) students who were taught in the usual way. The experimental study used the development of science processes and the acquisition of concepts. The results of the study showed that there were statistically significant differences between the average performance of the two groups in the tests of the development of the science processes and acquisition of the post-concepts. The experimental group was studied using the virtual laboratory.

Qaytit (2008) investigated the effect of using the dry laboratory in acquiring physical concepts and higher thinking skills among students in the basic stage in Jordan. The sample consisted of sixty-one (61) students who were selected according to the method of purpose. The study was divided into two groups: the first was an experimental group of thirty-one (31) students who were taught according to the dry lab method, and the second was headed by a female officer of thirty (30) students who were taught in the usual way of the acquisition of physical concepts and higher thinking skills. The results of the study showed that there were statistically significant differences between the mean performance of the two study groups in the tests of acquisition of physical concepts and higher thinking skills of the secondary group of the experimental study, which was studied using the dry laboratory strategy.

Mohammedi (2008) conducted a study aimed at investigating the effectiveness of virtual laboratories and their impact on a collection of different levels of female students. The sample consisted of seventy-three (73) students divided into two groups: the first was an experimental group of thirty-one (31) students who were taught according to dry lab method and the second was a female officer group of thirty-seven (37) students who were taught in the usual way. The results of the study showed that the experimental group was superior to the average 
test scores for the experimental group for all levels.

In 2007, he conducted a study aimed at identifying the effect of the use of computer labs on the achievement of students of the third year in a chemistry course in Saudi Arabia. The sample consisted of fortytwo (42) students; it was divided into two groups: the first was an experimental group of twenty-one (21) students who were taught according to the method of using computer labs, and the second was an officer of the twenty-one (21) students who were taught in the usual way. The study used an achievement test in chemistry. The results of the study showed that there were statistically significant differences between the average performances of the two study groups in the post-test tests, which are attributed to the experimental study group, which was studied using the computerized laboratory strategy.

The study of Williamson and Abraham (1995) examined the effect of computer use on the acquisition of chemical concepts in a sample of chemistry students. The study sample consisted of two groups: the first was computer-assisted and the second was taught in the usual manner. The study used an achievement test to acquire chemical concepts. The results of the study showed that there were statistically significant differences between the mean performance of the two study groups in the post-achievement test, which is attributed to the experimental study group, which was studied using the computer strategy.

\section{The Problem of the Study and its Questions}

Most of the teaching methods used by science teachers in general and in chemistry, especially narration and indoctrination, tend to make students receive information, memorize it without understanding it and absorb it, which impedes the interaction between the student and the teacher. Through the study of several modern methods of teaching, there has been a trend that has seen the interest in education based on the use of modern educational methods and modern technologies increase. This includes the use of computers in the classroom, through the continuous participation between students and computers, and the employment of modern software in education which deals with teaching methods, particularly those related to structural theory and active learning based on green learning theory. Many studies and research have encouraged the use of various new teaching methods. The researcher chose the method of the dry laboratory, which was noted to have received interest of many researchers. Also, the studies that claimed its effectiveness, the study of Qaitit (2008), recommended the importance of dry laboratory strategy and that further studies be carried out on the impact of the use of Dry Laboratory in teaching subjects such as chemistry. Also, the study of Samara, Al-Adaily, and Saudi Arabia (2018), recommended that studies be carried out to examine the effect of the dry laboratory in the acquisition of science operations.

The problem of the study is that there is an observed weakness in the level of academic achievement in chemistry, especially in the primary stage, through a survey conducted by the researcher in which he asked questions to a group of chemistry teachers. The result of the survey was the emphasis of teachers that the process of teaching chemistry in schools faces several difficulties and obstacles. To overcome them, the researcher saw the focus on the method of dry laboratory based on the theory of green education because of its importance in the teaching of chemistry, as it provides the students with opportunities to learn and experiment themselves and this helps to keep the material longer and improve the practical skills they have.

Despite the limitations of laboratory work and the emergence of modern education technology, which is based on the use of computer programs as an important component of teaching, the need to use computer as a teaching aid in chemistry has emerged as the computer provides the opportunity for experiments that are difficult to perform in the laboratory. The researcher identified the problem of studying the effect of the use of the dry laboratory based on the theory of green education in the teaching of chemistry in the acquisition of science and achievement in the tenth-grade students in Amman.

The answer to the main question of the study requires answering the following questions:

Question 1: Does the acquisition of science operations differ substantially among 10th grade students in Amman district, in accordance with the teaching strategy (dry laboratory, traditional method)?

Question 2: Does the achievement differ substantially among the students of the tenth grade in the Amman district according to the teaching strategy (dry laboratory and traditional method)?

\section{Hypotheses of the Study}

In order to answer the questions of the previous study, the two study hypotheses were formulated as follows: 1. There is no statistically significant difference at the level of significance $(\alpha=0.05)$ in the average marks of the tenth grade students in the test of science operations due to the dry laboratory method.

2. There was no statistically significant difference at the level of significance $(\alpha=0.05)$ in the mean scores of the tenth grade students in the achievement test due to the dry laboratory method.

\section{Purpose of the Study}

The aim of the study was to investigate the effect of the use of the dry lab based on the theory of green education 
in the teaching of chemistry in the acquisition of science and achievement in the tenth-grade students in Amman.

\section{The Importance of the Study}

The importance of the current study in theory and practice is as follows:

1. Employing computer technologies through simulation software, sound, image, and motion.

2. It may contribute to providing students with a constructive teaching strategy that helps to acquire science processes and increase the academic achievement in chemistry.

3. The present study presented models of the chemistry links of the chemistry class for the tenth grade.

\section{The Limitation of the Study}

1. Human limit : A sample of students of the tenth grade in the Amman district in the capital Amman.

2. The Spatial Limit: Amman city Brigade in the governorate of Amman the capital of Jordan .

3. Time Limit: The first semester of 2019/2018.

\section{Determinants of the Study}

The results of the present study are determined by the tools that were used to measure the acquisition of science and chemistry of the students.

\section{Terminology of Study}

Dry Lab: Conceptually defined as the use of computer software through the learner's implementation of the activities and experiments that cover the chemical bonds unit of the book of chemistry for the tenth grade to be taught by the Ministry of Education of Jordan for the academic year 2019/2018.

Science Operations: Conceptually defined as the ability to acquire students' knowledge processes through observation, measurement, classification, prediction, and use of numbers in chemistry. And a procedural measure of the degree to which the student received the test of science operations.

Achievement: Conceptually defined by access to a certain level of information gathering and skills required, measured by standardized tests or teacher reports (Ahmed, 2010). It was defined as a measure of the amount obtained by the students of the sample of the grades in the achievement test prepared by the researcher after their study of the unit of chemical links in chemistry for students of the experimental and control groups.

\section{Study Procedures}

The methodology of the study, its society, its representative sample, its tools, study variables, and the procedures followed by the researcher in the implementation of the present study were examined and processed statistically.

\section{Study Approach}

The study adopted the semi-experimental method for its relevance to the purposes of this study.

\section{Study Society}

The study population is composed of all public school students in Amman district in the capital, Amman.

\section{The study sample}

The sample of the study consisted of tenth-grade students, and a sample was selected from Khuraibah secondary school in Amman's Brigade in the governorate of Amman. They were divided into two groups: the first experimental number of twenty (20) students was taught using the method of dry laboratory based on the theory of green education, and the second officer heading the number of twenty (20) students were taught in the usual way.

\section{Study Tools}

To answer the questions of the study, a test was conducted for the scientific operations and the achievement test as follows:

\section{Test the Processes of Science}

The test of the processes of science, including observations, measurement, classification, inference, prediction and use of numbers, the use of spatial and temporal relations, communication, control of changes and interpretation of data, consists of (20) multiple choice types. 


\section{Validation}

In order to confirm the validity of the test, it was presented in its preliminary form, which consists of 20 paragraphs, to a group of arbitrators with experience in the science curriculum, to express their opinion on the extent of the test representation of the scientific processes, as well as the language formulation and its suitability to the level of students.

The test paragraphs were analyzed, and the difficulty and discrimination coefficient was calculated for each of the test paragraphs. Table 1 shows this.

Table 1. Difficulty and discrimination coefficients to test science processes

\begin{tabular}{|l|l|l|}
\hline Paragraph number & Coefficient of difficulty & Coefficient of discrimination \\
\hline 1 & 46.0 & 62.0 \\
\hline 2 & 51.0 & 42.0 \\
\hline 3 & 38.0 & 55.0 \\
\hline 4 & 42.0 & 52.0 \\
\hline 6 & 43.0 & 47.0 \\
\hline 7 & 42.0 & 48.0 \\
\hline 8 & 39.0 & 64.0 \\
\hline 9 & 40.0 & 52.0 \\
\hline 10 & 33.0 & 38.0 \\
\hline 11 & 50.0 & 38.0 \\
\hline 12 & 40.0 & 46.0 \\
\hline 13 & 39.0 & 86.0 \\
\hline 14 & 73.0 & 35.0 \\
\hline 15 & 38.0 & 71.0 \\
\hline 16 & 65.0 & 81.0 \\
\hline 17 & 40.0 & 64.0 \\
\hline 18 & 45.0 & 39.0 \\
\hline 19 & 60.0 & 80.0 \\
\hline 20 & 45.0 & 66.0 \\
\hline & 55.0 & 60.0 \\
\hline
\end{tabular}

The results of the analysis in Table 1 show that the values of the difficulty coefficients ranged from 0.33 to 0.73 , and the values of the discrimination coefficients ranged from 0.35 to 0.81 .

\section{Reliability of the Test}

The stability coefficient was calculated in two ways:

- The method of internal consistency, using the Kuder-Richardson 20 equation, to measure the internal consistency of the test questions and its value after adjustment $(0.86)$.

- The test-retest method, where the test was applied to a sample from the outside of the study sample. After two weeks, it was returned on the same sample, and the stability coefficient was calculated after extraction with Pearson correlation coefficient (0.82). Spearman-Brown was the stability factor (0.84).

The Collection Test

An achievement test consisting of (20) paragraphs of a multiple choice type was prepared.

\section{Validation}

To verify the validity of the test, it was presented in its preliminary form, which consists of 20 paragraphs, to a group of arbitrators with experience in the science curriculum, to express their opinions on the extent of the test for the behavioral objectives of the educational material, and the relevance of its paragraphs to the objectives of the subject level of students. In light of their observations, the wording of some test paragraphs has been modified. The test paragraphs were analyzed, and the difficulty and discrimination coefficient was calculated for each of the test paragraphs. Table 2 shows this. 
Table 2. Coefficient of difficulty and discrimination of the test achievement

\begin{tabular}{|l|l|l|}
\hline Paragraph number & Coefficient of difficulty & Coefficient of discrimination \\
\hline 1 & 45.0 & 69.0 \\
\hline 2 & 54.0 & 42.0 \\
\hline 3 & 41.0 & 55.0 \\
\hline 4 & 40.0 & 43.0 \\
\hline 5 & 35.0 & 42.0 \\
\hline 6 & 50.0 & 39.0 \\
\hline 7 & 50.0 & 40.0 \\
\hline 8 & 45.0 & 35.0 \\
\hline 9 & 39.0 & 50.0 \\
\hline 10 & 74.0 & 39.0 \\
\hline 11 & 52.0 & 40.0 \\
\hline 12 & 42.0 & 35.0 \\
\hline 13 & 39.0 & 50.0 \\
\hline 14 & 78.0 & 40.0 \\
\hline 15 & 38.0 & 39.0 \\
\hline 16 & 33.0 & 79.0 \\
\hline 17 & 44.0 & 39.0 \\
\hline 18 & 45.0 & 74.0 \\
\hline 19 & 40.0 & 69.0 \\
\hline 20 & 52.0 & 64.0 \\
\hline
\end{tabular}

The results of the analysis in Table 2 indicate that the values of the difficulty coefficients ranged from 0.35 to 0.78 and the values of the coefficient of distinction between 0.33 and 0.74 were acceptable for the study.

\section{Reliability of the Test}

The stability factor will be calculated in two ways:

- The internal consistency method, using the Kuder-Richardson 20 equation, to measure the internal consistency of the test questions and its value after adjustment (0.84).

- The test-retest method, where the test was applied to a sample from the outside of the study sample. After two weeks, it was returned on the same sample, and the stability coefficient was calculated after extraction with Pearson correlation coefficient (0.80) (0.81), which is a suitable stability coefficient for research purposes.

\section{Results and Discussion}

Table 3. Mathematical averages and standard deviations of the scores of students of the two study groups Experimental and control the test of science processes

\begin{tabular}{|l|l|l|l|l|l|l|l|}
\hline the group & the & \multicolumn{2}{|c|}{ Pre - Test } & Standard & \multicolumn{2}{|c|}{ Post-test } & Standard \\
\cline { 6 - 8 } & number & $\begin{array}{l}\text { Standard } \\
\text { error }\end{array}$ & $\begin{array}{l}\text { standard } \\
\text { deviation }\end{array}$ & & $\begin{array}{l}\text { Standard } \\
\text { mean }\end{array}$ & $\begin{array}{l}\text { standard } \\
\text { deviation }\end{array}$ & \\
\hline Experimental & 20 & 8.30 & 2.57 & 0.58 & 15.85 & 1.98 & 0.44 \\
\hline Control & 20 & 8.00 & 3.47 & 0.77 & 11.25 & 2.53 & 0.56 \\
\hline
\end{tabular}

Table 3 shows that there is a statistically significant difference between the mean scores of the students of the experimental and control groups. The experimental mean of the experimental group studied using the dry laboratory strategy in the post application was to test the operations of science. The highest was 15.85 . The arithmetic average of the control group studied in the normal way (11.25). In order to detect the significance of the differences, the ANCOVA analysis was used. Table 4 shows the results of the analysis. 
Table 4. The results of the associated variance (ANCOVA) for the differences between the average achievements of the two study groups

Test the processes of science in chemistry

\begin{tabular}{|l|l|l|l|l|l|l|}
\hline $\begin{array}{l}\text { Source of } \\
\text { Contrast }\end{array}$ & $\begin{array}{l}\text { Total } \\
\text { squares }\end{array}$ & $\begin{array}{l}\text { Degree of } \\
\text { freedom }\end{array}$ & $\begin{array}{l}\text { Average } \\
\text { squares }\end{array}$ & $\begin{array}{l}\text { Calculated value } \\
(\mathrm{P})\end{array}$ & $\begin{array}{l}\text { Level } \\
\text { significance }\end{array}$ & $\begin{array}{l}\text { Aita } \\
\text { box }\end{array}$ \\
\hline Pre-test & 2.86 & 1 & 2.86 & --- & --- & --- \\
\hline $\begin{array}{l}\text { Teaching } \\
\text { strategy }\end{array}$ & 208.609 & 1 & 208.61 & 39.79 & $0.00^{* *}$ & 519.0 \\
\hline The error & 193.44 & 37 & 5.23 & --- & --- & -- \\
\hline Overall rate & 407.90 & 39 & --- & --- & --- & -- \\
\hline
\end{tabular}

** means statistical significance at $((\alpha=0.05)$

Table 4 shows that there is a difference in the post-application of the test of science operations in favor of the experimental group. The value of $\mathrm{P}$ calculated is 39.79 at the level of significance $(0.00)$, which is less than $\alpha$ $=0.05$. The first hypothesis is rejected, and the alternative hypothesis is accepted, that indicates a statistically significant difference between the mean scores of the experimental group and the control group. This means that the difference in the post-application of the test of science processes was the result of the different method of teaching for the benefit of the experimental group, which was studied using the dry laboratory strategy when compared with the control group studied in the usual way. The effect size was Eta Squared $=0.519$, which reflects the percentage (effect) of the use of dry laboratory on the acquisition of students of the experimental group of science operations, which means that the dry laboratory method has affected $51.9 \%$ in the test skills of science operations. And that teaching in the dry laboratory has a positive effect on the test of the science processes of the students of the experimental group, outperforming the usual method, which may be because the students in the experimental group preferred to use the dry laboratory strategy to get rid of the routine, which overshadows the traditional method of teaching. The Dry Lab is designed to raise the students' attention, their interaction in the lesson, the knowledge of the concepts, and the increase in their cognitive abilities in expanding the various information and concepts. The results showed that the dry laboratory method showed a new impact on students, allowing each student to see the experience and thus increase the interaction with the educational material, as well as the excitement and interest, which worked to raise the motivation of students towards learning, and showed the students a keen interest to learn about Dry Lab Road. The results of the present study were in line with the results of the Qutit study (2008) and the study of Dar Ibrahim (2014), which confirmed that the dry laboratory method has a positive impact on the development of science processes.

The second hypothesis: There is no statistically significant difference at the level of significance $(\alpha=0.05)$ in the average marks of the tenth grade students in the achievement test due to the teaching strategy (dry laboratory).

To answer this, the arithmetical averages and the standard deviations of the post-performance of the test were extracted. Table 5 shows the results of the analysis.

Table 5. Mathematical averages and standard deviations of the scores of students of the two study groups Experimental and control on the collection test

\begin{tabular}{|c|c|c|c|c|c|c|c|}
\hline \multirow[t]{3}{*}{ the group } & \multirow{3}{*}{$\begin{array}{l}\text { the } \\
\text { number }\end{array}$} & \multicolumn{2}{|c|}{ Pre-test } & \multirow{3}{*}{$\begin{array}{l}\text { Standard } \\
\text { error }\end{array}$} & \multirow{2}{*}{\multicolumn{2}{|c|}{ Post-test }} & \multirow{3}{*}{$\begin{array}{l}\text { Standard } \\
\text { error }\end{array}$} \\
\hline & & \multirow{2}{*}{$\begin{array}{l}\text { Standard } \\
\text { mean }\end{array}$} & \multirow{2}{*}{$\begin{array}{l}\text { Standard } \\
\text { deviation }\end{array}$} & & & & \\
\hline & & & & & $\begin{array}{l}\text { Standard } \\
\text { Mean }\end{array}$ & $\begin{array}{l}\text { Standard } \\
\text { Deviation }\end{array}$ & \\
\hline Experimental & 20 & 9.15 & 3.16 & 0.70 & 17.10 & 4.72 & 1.05 \\
\hline Control & 20 & 8.60 & 3.23 & 0.72 & 12.55 & 5.17 & 1.15 \\
\hline
\end{tabular}

Table 5 shows that the experimental mean of the experimental group, which was studied using the dry laboratory method in the post-application of the collection test, was the highest (17.10), while the arithmetic average of the control group studied in the normal manner (12.55). To detect the significance of the differences, ANCOVA was used to analyze the associated variance. Table 6 shows the results of the analysis.

Table 6. The results of the associated variance (ANCOVA) for the differences between the average achievement of the two study groups on the collection test

\begin{tabular}{|l|l|l|l|l|l|l|}
\hline $\begin{array}{l}\text { Source of } \\
\text { Contrast }\end{array}$ & $\begin{array}{l}\text { Total } \\
\text { squares }\end{array}$ & $\begin{array}{l}\text { The degree of } \\
\text { freedom }\end{array}$ & $\begin{array}{l}\text { Average } \\
\text { squares }\end{array}$ & $\begin{array}{l}\text { Calculated } \\
\text { value (P) }\end{array}$ & $\begin{array}{l}\text { Level } \\
\text { significance }\end{array}$ & $\begin{array}{l}\text { Aita } \\
\text { box }\end{array}$ \\
\hline Pre-Test & 32.69 & 1 & 32.69 & --- & --- & -- \\
\hline Teaching strategy & 238.34 & 1 & 238.34 & 9.79 & $0.00 * *$ & 209.0 \\
\hline The error & 900.05 & 37 & 24.34 & --- & --- & -- \\
\hline Overall rate & 1139.77 & 39 & --- & --- & --- & -- \\
\hline
\end{tabular}

** means statistical significance at $(\alpha=0.05)$ 
Table 6 shows that there is a difference in the post-application of the collection test in favor of the experimental group. The value of $\mathrm{P}$ calculated is 9.79 at the level of significance $(0.00)$, which is less than $(\alpha=$ 0.05). This result negates the second null hypothesis and accepts the alternative hypothesis that indicates a statistically significant difference between the mean scores of the experimental group students taught by the dry laboratory and the grades of the control group students who were taught in the usual way. This means that the difference in the post-implementation of the collection test differed according to the method of teaching. It was in favor of the experimental group studied using the dry laboratory strategy when compared with the control group studied in the usual way. The dry laboratory has affected $20.9 \%$ in the achievement test. The dry laboratory strategy has had a positive effect on the achievement test of the experimental group, surpassing the usual method. This may be because the experimental group students, who studied using the dry laboratory strategy, were able to simulate the tools needed to implement the practical experiments and interacted with it freely through the computer screen because it includes regular and sequential steps. This helped students to progress in learning to the extent appropriate to his abilities and speed, which allows him to get the information himself. This finding can be attributed to the fact that teaching by using the laboratory has made students focus on their activity, which stimulated them to learn more. As a result of their love and internal motivation to learn, they accept practical experiments more than once. The results of the current study were in line with the results of the 2007 study and the Muhammadi study (2008), all of which confirmed that the dry laboratory strategy had a positive impact on student achievement.

\section{Conclusions}

In light of the results of the study, the researcher concluded that there was an effect on the use of the dry lab method, based on the theory of green education in the teaching of chemistry in acquiring the processes of science and achievement, among the tenth grade students in Amman compared to those who studied in the traditional way.

\section{Recommendations}

In light of the results of this study, the researcher recommends the use of the dry lab method in teaching chemistry and various scientific materials and training the teachers and supervisors of the laboratories in schools on how to implement this method. The curriculum should include activities and experiments that employ the learning environments in the educational process.

\section{Arabic References}

Ahmed Ali Abdul Hamid (2010). Educational achievement and its relation to Islamic values. Beirut: Hasan Modern Library.

Ahmed Samir, Hassan Mohamed \& Gamal El Din Najwa (2014). Green economy ... Concept and requirements in Education. Journal of Educational Sciences, 22 (3), 427-453.

Al-Bawi Magda, Salem Fayez \& Ghazi Ahmad (2016). The impact of virtual laboratory use on theoretical performance and scientific students of the fifth grade scientific. Conference: Education Technology and Global Challenges for Education In Cairo, July, 2016.

Al-Far, Ibrahim (2004). Computer literacy and the challenges of the early 21st century. Cairo: Dar Al-Fikr Arabi.

Ali Mohamed El Sayed (2003). Practical Education and Teaching Science Amman: Dar Al - Masirah for Publishing and Distribution.

Al- Odhayli, Faisal (2007). The Effect of Using Computerized Labs on the Achievement of Third Year Students in Chemistry Course in Saudi Arabia. Unpublished Master Thesis, College of Education, King Saud University, Saudi Arabia.

Mohammedi Amal (2008). Effectiveness of the virtual lab on the achievement of different levels of second graders Secondary in chemistry. Unpublished MA, Faculty of Education and Human Sciences, Taibah University, Medina.

National Center for e-Learning at the University Council (2010). Guidance and progress model for a request for availability: A virtual laboratory for scientific courses in Egyptian universities. From the site http: //ecenter.mans.edu.eeldoc/virtual labs.ndf

Qutait Ghassan (2008). The effect of using the dry laboratory on the acquisition of physical concepts and higher thinking skills. Request for the basic stage in Jordan. Journal of Scientific Education, 11 (2) 76-100.

Salamah Abdel Hafez (2016). Means of Communication and Technology in Education. Amman: Dar Al Fikr Publishing and Distribution.

Samara Nawaf, Al - Adaily Abdul Salam, \& Saudi Taha (2018). Effectiveness of teaching dry laboratory in the acquisition of chemical concepts of students enrolled in the general chemistry course at Mutah University. University Journal Hussein Bin Talal Research. 4 (2), 131-112.

Yasmin, "Dar Ibrahim" (2014). The impact of the use of the virtual laboratory of science experiments in the 
development of science processes and the acquisition of concepts among fifth graders in Palestine. Unpublished MA, Faculty of Education, An-Najah University, Palestine.

Zaitoun Ayesh Mahmoud (2005). Methods of teaching science. Amman: Dar Al Shorouk.

\section{International references}

Willamson, V. \& Abraham, M. (1995). The Effect of Computer Animation and the Practical Mental Modeles of College Chemistry Students. Journal of Research in Science Teaching, 32 (5), 521-534.

Marournaltinez, A. (2003). Learning in Chemistry with Virtual Laboratories. Journal of Chemical Education, 80 (3), 346-352. 